\title{
VALIDATION OF UNSTABLE DISCRETE EVENT MODELS
}

\author{
Hans-Peter Barbey \\ University of Applied Sciences Bielefeld \\ 33602 Bielefeld, Germany \\ E-mail: hans-peter.barbey@fh-bielefeld.de
}

\section{KEYWORDS}

Simulation, close-loop control, discrete event model, validation, FFT analysis.

\begin{abstract}
Logistic systems can be designed as a push-system or a pull-system. In a pull-system one parameter e.g. the stock items has to be close-loop controlled. It will be shown that the close-loop controlled model can work in an unstable manner like a "logistic oscillating circuit". In comparison with a close-loop controlled electronic system the elements of a logistic system have relatively long dead times. In discrete event simulation there is no method to optimally calculate the parameters of the system also taking account of the dead times. Furthermore, there is no validation technique to date, which can determine the unstable behavior of the system. In many different areas of engineering the FFTanalysis is a frequently used method. It will be shown that the FFT analysis is a suitable method to determine the unstable behaviour of discrete event simulation models. However, FFT analysis is only a method to determine the unstable behaviour; the elimination can only be done by trial and error.
\end{abstract}

\section{INTRODUCTION}

Discrete event simulation is a frequently used method for designing new, complex production systems. The advantage of this method is that all elements of the system can be described with only a few parameters. Objectives of such a simulation study are to obtain knowledge of, for example, cycle times or utilisation of the machinery. There are numerous commercially available programs for this.

The execution of a complete simulation study is described in VDI 3633. An important point within a simulation study is the validation of the model and the results. There is no generally applicable guideline for this. Depending on the particular project, different methods can be applied. A good summary of all methods is in Rabe et al 2008 (table 1).

\section{STATE OF THE ART}

Push-systems are often used for the management of a production system. These systems are producing goods without a customer order. Therefore, the stock in such a system is relatively high. To reduce stock, a pull-system is the better solution. Here, the production only starts on demand. The higher the demand, the faster is the production rate. These systems are close-loop controlled.

Table 1: Validation methods (according to Rabe et al.)

\begin{tabular}{|c|c|c|c|c|c|c|c|c|}
\hline & 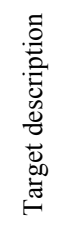 & 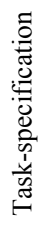 & 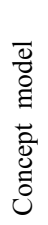 & 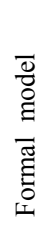 & 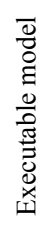 & 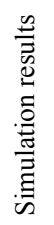 & 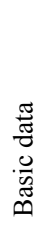 & 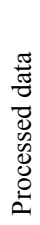 \\
\hline Animation & & & & & $\mathrm{X}$ & $\mathrm{X}$ & & \\
\hline Review & $\mathrm{X}$ & $\mathrm{X}$ & $\mathrm{X}$ & $\mathrm{X}$ & $\mathrm{X}$ & $\mathrm{X}$ & $\mathrm{X}$ & $\mathrm{X}$ \\
\hline $\begin{array}{l}\text { Dimensional } \\
\text { Consistency } \\
\text { test }\end{array}$ & & & & $\mathrm{X}$ & $\mathrm{X}$ & $\mathrm{X}$ & $\mathrm{X}$ & $\mathrm{X}$ \\
\hline $\begin{array}{l}\text { Event validity } \\
\text { test }\end{array}$ & & & & & $\mathrm{X}$ & & & \\
\hline $\begin{array}{l}\text { Fixed value } \\
\text { test }\end{array}$ & & & & $\mathrm{X}$ & $\mathrm{X}$ & $\mathrm{X}$ & & \\
\hline $\begin{array}{l}\begin{array}{l}\text { Extreme } \\
\text { condition test }\end{array} \\
\end{array}$ & & & & $\mathrm{X}$ & $\mathrm{X}$ & $\mathrm{X}$ & & \\
\hline Monitoring & & & & & $\mathrm{X}$ & $\mathrm{X}$ & & $\mathrm{X}$ \\
\hline Desk checking & $\mathrm{X}$ & $\mathrm{X}$ & $\mathrm{X}$ & $\mathrm{X}$ & $\mathrm{X}$ & $\mathrm{X}$ & $\mathrm{X}$ & $\mathrm{X}$ \\
\hline $\begin{array}{l}\text { Sensitivity } \\
\text { Analysis }\end{array}$ & & & & & $\mathrm{X}$ & $\mathrm{X}$ & & $\mathrm{X}$ \\
\hline $\begin{array}{l}\text { Statistical } \\
\text { Techniques }\end{array}$ & & & & & $\mathrm{X}$ & $\mathrm{X}$ & $\mathrm{X}$ & $\mathrm{X}$ \\
\hline $\begin{array}{l}\text { Structural } \\
\text { walkthrough }\end{array}$ & $\mathrm{X}$ & $\mathrm{X}$ & $\mathrm{X}$ & $\mathrm{X}$ & $\mathrm{X}$ & $\mathrm{X}$ & $\mathrm{X}$ & $\mathrm{X}$ \\
\hline $\begin{array}{l}\text { Internal } \\
\text { validity test }\end{array}$ & & & & & $\mathrm{X}$ & $\mathrm{X}$ & & \\
\hline $\begin{array}{l}\text { Sub model } \\
\text { testing }\end{array}$ & & & $\mathrm{X}$ & $\mathrm{X}$ & $\mathrm{X}$ & & & \\
\hline Trace analysis & & & & & $\mathrm{X}$ & & & \\
\hline Turing test & & & & & $\mathrm{X}$ & & & \\
\hline $\begin{array}{l}\text { Cause-effect } \\
\text { graph }\end{array}$ & & & $\mathrm{X}$ & $\mathrm{X}$ & $\mathrm{X}$ & & & \\
\hline Face validity & $\mathrm{X}$ & $\mathrm{X}$ & $\mathrm{X}$ & $\mathrm{X}$ & $\mathrm{X}$ & $\mathrm{X}$ & $\mathrm{X}$ & $\mathrm{X}$ \\
\hline $\begin{array}{l}\text { Predictive } \\
\text { validation } \\
\end{array}$ & & & & & $\mathrm{X}$ & & & \\
\hline $\begin{array}{l}\text { Comparison to } \\
\text { other models }\end{array}$ & & & & & $\mathrm{X}$ & $\mathrm{X}$ & & \\
\hline $\begin{array}{l}\text { Historical data } \\
\text { validation }\end{array}$ & & & & & $\mathrm{X}$ & & & \\
\hline
\end{tabular}

These close-loop controlled systems can of course also be designed using discrete event simulation. As there is usually no special module for this, the controller has to be designed using a special program code.

First, it is necessary to point out the differences between a logistics close-loop controlled system and close-loop controlled systems in for example automation technology. In the automation technology, the systems are designed using electronic modules. The signals in 
these systems are therefore electric currents or voltages. Therefore the speed of the signals is practically infinite. In contrast, the speed of the signal in a logistics system is very low. The speed of a conveyor is low or the processing time on a production machine is high. Thus, the speed of the signal which is connected with the flow of objects through the production system is very low. Described in terms of control technology, the time difference between the entry of an object or signal to a machine and the exit is the dead time. It is generally known that dead times in a close-loop controlled system can result in oscillations and thus unstable systems. There are methods in control technology to design the parameters of a system so that these oscillations can be prevented. These methods could not be applied in the discrete event simulation due to missing mathematical relationship between the system parameters.

\section{UNSTABLE DISCRETE MODEL OF A LOGISTIC SYSTEM}

First, it is necessary to demonstrate, that unstable behaviour can also occur in logistics systems. A very simple model will be designed for this (fig.1): a production system is fed by a transport system. The production system delivers the goods to a stock. The stock output rate is constant. The difference between the current stock and the target stock is the parameter which controls the transport. The higher the difference, the faster is the transport.

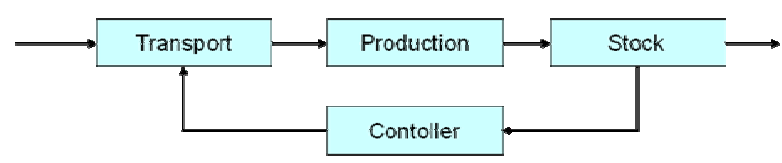

Figure 1: Simple close-loop controlled production system

The system is designed with the following parameters:

- The production system is fed by a transport system

- The flow rate of the transport system is closeloop controlled

- The production time of one unit is 1 day

- The production has an infinite capacity

- The target stock is 15 units

- The stock has a infinite capacity

- The stock output rate is constant 1 unit/4.8h

This system is close-loop controlled by a controller with the following parameters:

- The current stock is recorded once per day

- The flow rate of the transport is calculated with a delay of one half day
- The difference of the stock is fed into the production system by the transport system on the next day

A discrete event model is created using these values (Figure 2). A similar model is presented in Barbey.

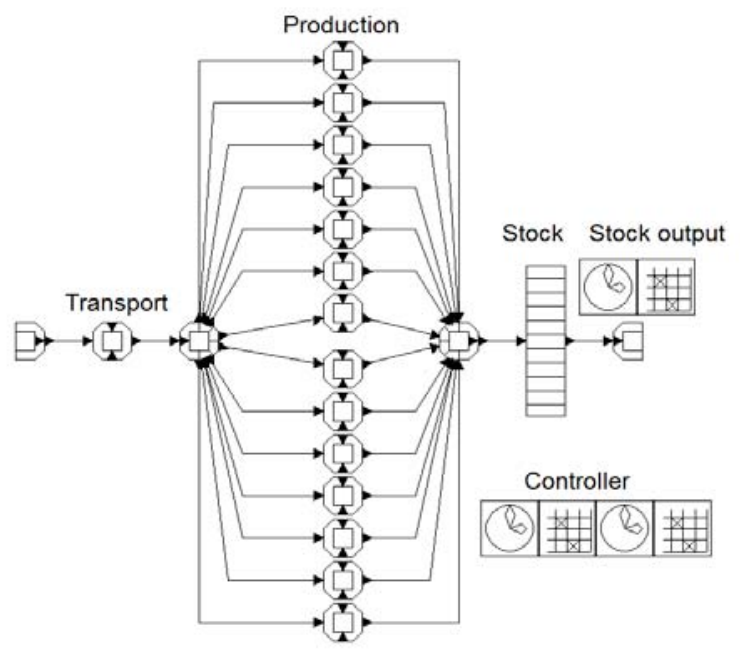

Figure 2: Discrete event model designed with DOSIMIS

In the following diagram the results for the stock are recorded over a period of 5 weeks.

At the very beginning the controller is switched off. The stock has a constant figure of 5 units here. After approx. one week, the controller is switched on. Then the stock has in average the target value. However, it is overlaid with an oscillation with amplitude of 7 units (Figure 3). This model demonstrates that an unstable behavior in logistic systems can occcur, if an unsuitable set of parameters is applied. All input parameters are constant, but the stock is only constant on average. The model is acting like a "logistic oscillating circuit".

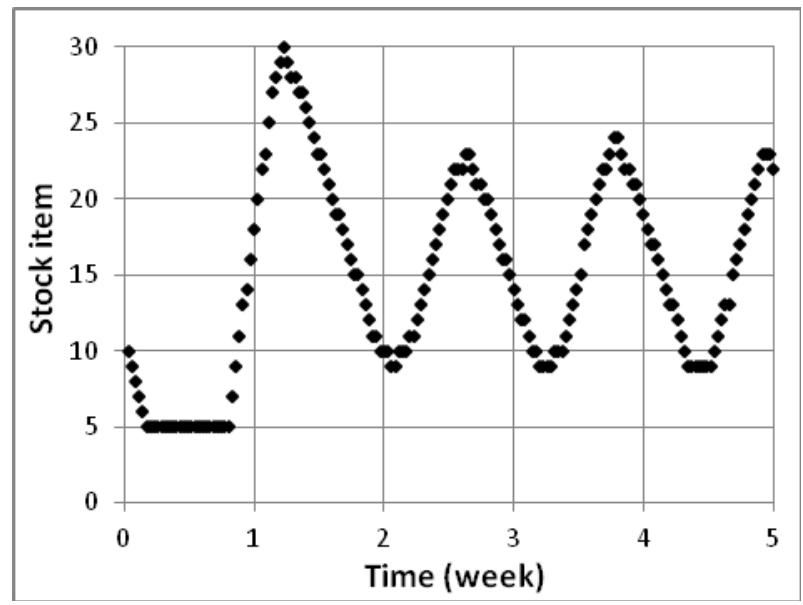

Figure 3: Stock in the close-loop controlled discrete event model 


\section{VALIDATION}

If unstable behavior can be produced in one model, then it is also possible to produce unstable behavior in any other model. Therefore validation of the model is an important question.

According Table 1 there are many validation methods, which can be applied. However, only reviewing of the results is suitable for this model. However, this model has been designed as simple as possible with the only objective of indicating an error: in this case an unstable behavior. It is also obvious that this error will be found with the selected validation method. However the models are generally much more complex and the unstable behavior is thus possibly not immediately visible.

For the next simulation test a second model will be created. This model has a modified controller and an additional stock output:

- The actual stock is recorded once per day

- The flow rate of the transport is calculated immediately

- There is an additional stock output each $1.4 \mathrm{~d}$.

- The additional output is a random number between 4 and 8 .

The results are shown in Figure 4. The results seems to be periodic. There must be a periodic part in, because the additional stock output is periodic. But there is no method according to Table 1 in this case which detects the unstable behavior of the model.

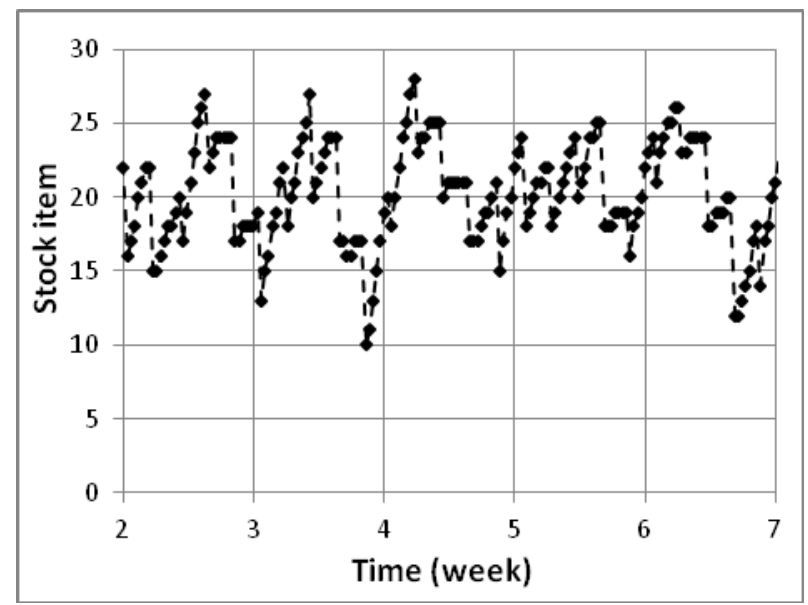

Figure 4: Stock with an additional output

Therefore, a new validation method must be found. In many areas of engineering the Fast-Fourier-Transform (FFT) is a frequently used method to analyze dynamic processes. This method states that each periodic signal can be compiled from a sum of sine- and cosinefunctions. The mathematical theory for this method is described in Brigham 1997.

To demonstrate the principle of the method, the FFTAnalysis is initially applied to the first model with the constant stock output. The result of the FFT-analysis, which have been produced here by using Excel are shown in Figure 5. The frequency range was analysed up to a frequency of $21 / \mathrm{d}$.

There is only one peak at a frequency of $0.12 \mathrm{1} / \mathrm{d}$. The same result can be obtained from the consideration of Figure 3. This frequency is the characteristic frequency of the unstable system. The application of the FFTanalysis to this simple model demonstrates, that this method is suitable for validation of discrete event models.

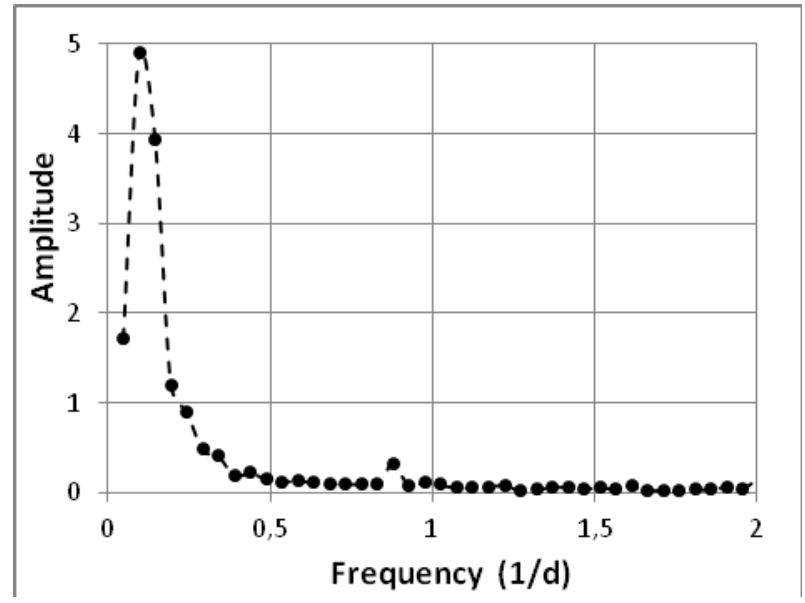

Figure 5: FFT-analysis with Excel for the first model

The unstable behavior of the second model is not visible in Figure 4. Therefore, the FFT-analysis is now applied to the results. The diagram in Figure 6 shows some typical characteristics of the model.

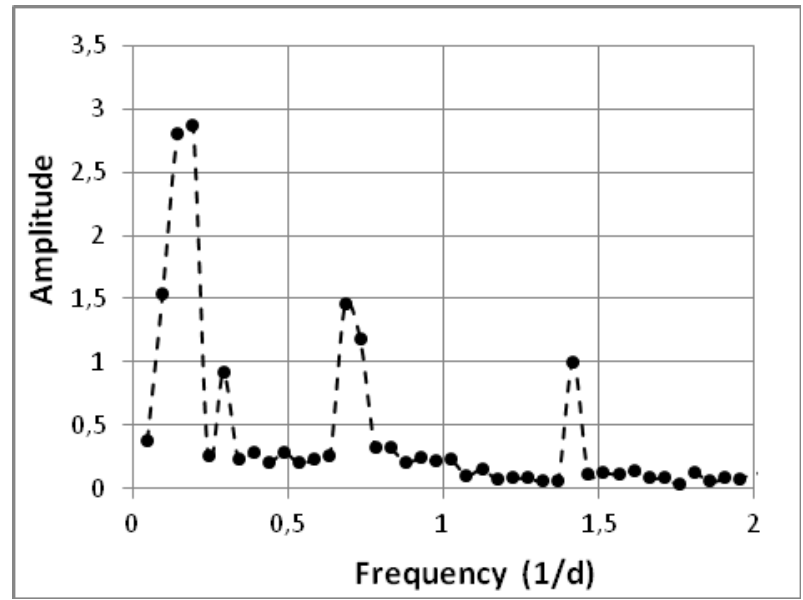

Figure 6: FFT-analysis with an additional output

There is one peak at a frequency of $0.71 / \mathrm{d}$. This is related to the additional output which has exactly this frequency. A second peak is at a frequency of $1.41 / \mathrm{d}$ which is double the frequency of the stock output. An extension of the frequency range would show additional peaks at all frequency multiples of the output. 
However, the largest peak is at a frequency of $0.151 / \mathrm{d}$. This peak cannot be explained by the additional output, it is related to the unstable behavior of the model itself. Using the FFT-analysis it is possible to identify unstable behavior of a discrete model. For this, each characteristic frequency has to be compared with the parameters of the model. In this case, the additional output is a parameter which produces a periodic signal. Threfore, this frequency and its multiples can be excluded. All other frequencies which could not be explained with the parameters of the model show an unstable behavior of the model.

However, the instable behavior cannot be eliminated using the FFT-analysis, as there is no functional relationship between the model parameters. The elimination of the unstable behavior can only be realized by trail and error. A variation of the parameters and a following FFT-analysis shows wether the results are satisfactory.

\section{OPTIMISATION}

Optimisation is always project-specific. Each model has a specific set of parameters which can be changed individually. The model is now only used to demonstrate how unstable behaviour can be eliminated by using the Fourier analysis.

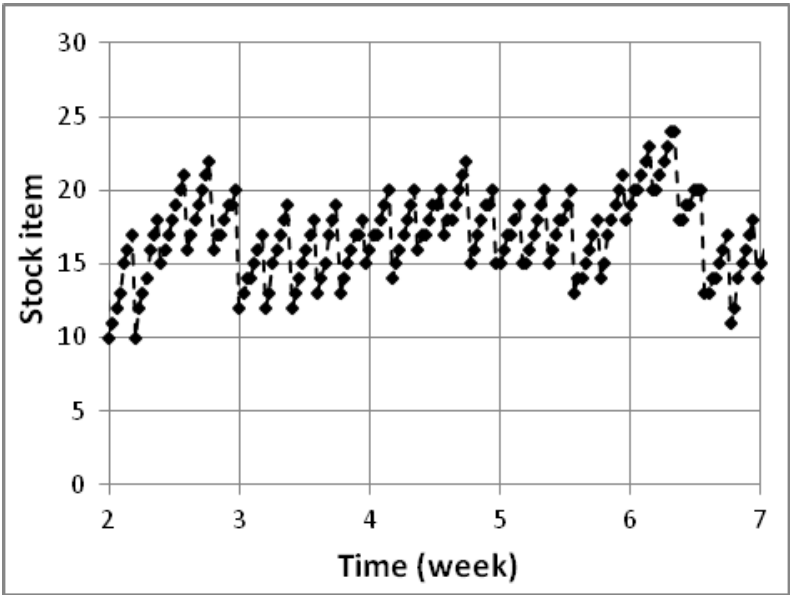

Figure 7: Stock with the modified controller

In the original model, the controller was designed so that the difference in the stock is supplied by the transport system to the production system on the next day. Now the controller will be modified so that only one third of the difference will be supplied to the production system on the next day. Figure 7 shows the stock with the modified controller. Compared with Figure 4, the fluctuation of the stock is reduced. Figure 8 shows the Fourier analysis for this.

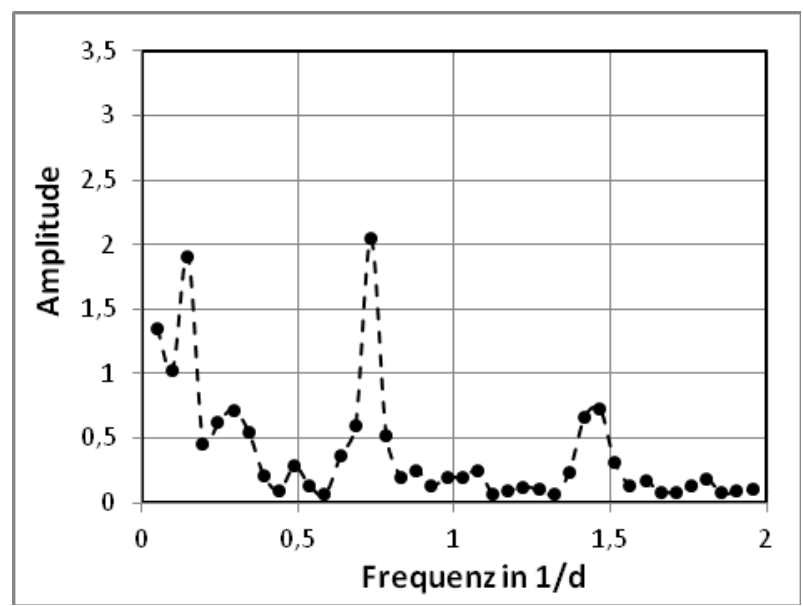

Figure 8: FFT analysis of the modified model

The peak at a frequency of $0.151 / \mathrm{d}$ is clearly reduced but still exists. All other peaks caused by the additional stock output are still there. This demonstrates an improvement, but the optimum has not yet been reached. Therefore, further variation of the parameters has to be done.

This procedure shows that the Fourier analysis is suitable for finding the instability of a model and optimising it afterwards.

\section{REFERENCES}

Barbey, H.-P. 2008. "Simulation des Stabilitätsverhaltens von Produktionssystemen am Beispiel einer lagerbestandsgeregelten Produktion." Proceedings of the 2008 ASIM-conference, Berlin.

Brigham, E.O.. 1997. FFT-Anwendungen. R.Oldenburg Verlag, München.

Rabe M., S. Spiekermann, S. Wenzel. 2008. Verifikation und Validierung in Produktion und Logistik. Springer Verlag, Berlin. Heidelberg.

VDI 3633. Simulation von Logistik-, Materialfluss- und Produktionssystemen. 2000, Beuth Verlag, Berlin.

\section{AUTHOR BIOGRAPHIES}

HANS-PETER BARBEY was born in Kiel, Germany, and went to the University of Hannover, where he studied mechanical engineering and obtained his degree in 1981. At the same university he obtained his doctorate in 1987 . He worked for 10 years for different companies for plastic machinery and plastic processing before moving in 1997 to the University of Applied Sciences Bielefeld. There, he is teaching transportation technology, plant planning and discrete simulation. His research is focused on the simulation of production processes.

His e-mail address is:

hans-peter.barbeyafh-bielefeld. de

And his Web-page can be found at

http://www.fh-bielefeld.de/fb3/barbey 